\title{
Potassium-sparing Agents during Diuretic Therapy in Hypertension
}

\author{
T. J. McKENNA, J. F. DONOHOE, T. G. BRIEN, J. J. HEALY, B. St. J. CANNING, \\ F. P. MULDOWNEY
}

normal outpatient life with no restrictions on dietary intake other than the elimination of free added salt at table.

\begin{abstract}
Summary
Three pharmacological agents in use as "potassiumsparing" drugs have been tested by serial measurements of total exchangeable potassium $\left(K_{E}\right)$ during 4 to 12 weeks of oral diuretic therapy in hypertensive subjects. Triamterene seemed ineffective in the dosage used (50 $\mathrm{mg}$ twice daily). Spironolactone (25 $\mathrm{mg}$ twice daily) reduced $K$ loss to a considerable extent, while Slow-K (32 mEq daily) completely reversed previous $K_{E}$ deficits. Plasma $K$ levels were a poor indication of degree of $K_{E}$ restoration.
\end{abstract}

\section{Introduction}

Depletion of body potassium during oral diuretic therapy may theoretically be prevented by a number of therapeutic agents. In practice, however, the efficacy of these procedures remains in doubt, being based mostly on occasional measurements of serum potassium without reference to external balance or whole body stores. Since we recently found a significant decrease in total exchangeable potassium $\left(\mathrm{K}_{\mathrm{E}}\right)$ in hypertensive subjects taking oral chlorthalidone (Healy et al., 1970) we decided to investigate the potassium restorative effect, if any, of three commonly used therapeutic preparations in this type of subject. The agents chosen were: (1) a "potassium-sparing" diuretic, triamterene (Dytac), (2) an aldosterone antagonist, spironolactone (Aldactone-A), and (3) oral potassium supplementation with Slow-K tablets.

\section{Subjects and Methods}

Studies were performed on 23 hypertensive subjects with good renal function. An arbitrary assessment of "essential" hypertension was made as previously described (Healy et al., 1970). The initial pretherapy values of the subjects studied are summarized in Table I. The methods of determining exchangeable sodium $\left(\mathrm{Na}_{\mathrm{E}}\right)$, exchangeable potassium $\left(\mathrm{K}_{\mathrm{E}}\right)$, plasma potassium $\left(\mathrm{K}_{\mathrm{P}}\right)$, and mean blood pressure have been previously described as were the statistical methods used (Healy et al., 1970). In the intervals between measurements each subject carried on a

\section{St. Vincent's Hospital, Dublin 4}

T. J. McKENNA, M.B., B.CH., Research Fellow, Department of Metabolism J. F. DONOHOE, M.B., B.CH., Research Fellow, Department of Metabolism T. G. BRIEN, M.sc., Physicist, Isotope Department

J. J. HEALY, M.D., M.R.c.P., Fellow of the Medical Research Council of Ireland

B. St. J. CANNING, M.B., ch.B., Research Fellow, Department of Metabolism

University College, Dublin 4

F. P. MULDOWNEY, M.D., M.R.C.P.ED., Research Professor of Medicine
The subjects were divided randomly into three groups as follows:

Chlorthalidone with Triamterene (C. + T.).-Chlorthalidone 100 $\mathrm{mg}$ orally on alternate days and triamterene $50 \mathrm{mg}$ orally twice daily were given to six subjects (three male and three female). $\mathrm{K}_{\mathrm{E}}, \mathrm{Na}$, and $K_{P}$ measurements were made before therapy, at 3-6 weeks (mean 4), and at 8-11 weeks (mean 9) after starting therapy.

Chlorthalidone with Spironolactone (C. + S.).-Chlorthalidone $100 \mathrm{mg}$ on alternate days and spironolactone $25 \mathrm{mg}$ twice daily were given orally to 10 subjects (five females and five males). $K_{E}, K_{P}$, and mean B.P. measurements were made before therapy and at 5-8 (mean 7) and 11-14 (mean 12.5) weeks after starting therapy. Two subjects were not maintained on spironolactone beyond the 12th week because of painful gynaecomastia.

Chlorthalidone with Slow- $K(\mathrm{C}$. $+\mathrm{K}$.).-Seven subjects (three female and four male) who had been on chlorthalidone therapy alone for 8-15 weeks (mean 11) were studied. These subjects had lost more than $6 \%$ of their total body potassium as assessed by serial $\mathrm{K}_{\mathrm{E}}$ measurements (see Table II of previous communication Healy et al., 1970). Slow-K tablets each containing $8 \mathrm{mEq}$ of potassium as potassium chloride were given to these subjects for an additional 5-15 weeks (mean 11), while chlorthalidone therapy was continued. Each patient received two Slow- $\mathrm{K}$ tablets twice daily $(32 \mathrm{mEq} \mathrm{K}+$ daily). $\mathrm{K}_{\mathrm{E}}$ measurement was repeated in each subject at the end of this time.

\section{Results}

Group C. + T.-The mean alterations with S. D. in $\mathrm{K}_{\mathrm{E}}$, $K_{E} / \mathrm{kg}$ body weight, $K_{P}$, and mean B.P. at 3-6 and 8-11 weeks in six subjects are summarized in Table II. $\mathrm{Na}_{\mathrm{E}}$ changes are included for five subjects. All measurements decreased significantly with the exception of $\mathrm{Na}_{E}$ at 3-6 weeks. The degree of change in $K_{E}, K_{E} / \mathbf{k g}$ body weight, and $K_{P}$ in subjects treated with chlorthalidone alone in the initial part of this study (Healy et al., 1970) is compared with these subjects in Table V. No difference is seen in the two groups. $K$ loss apparently increased with the duration of study in both groups.

Group C. + S.-The mean alterations with S. D. in $\mathrm{K}_{\mathrm{E}}$, $K_{E} / \mathrm{kg}$ body weight, $K_{P}$, and mean B.P. at 5-8 and 11-14 weeks in 10 subjects are summarized in Table III. Comparison between these alterations and those induced by chlorthalidone alone are made in Table $\mathrm{V}$. The magnitude of the potassium loss in this group was considerably less than that in the other groups studied. The variance within all groups was such that no statistically valid statement can be made on whether the addition of spironolactone to chlorthalidone prevents the potassium depletion which occurs with this latter drug. The results, however, are strongly suggestive that this is so. Mean B.P. fell significantly at $11-14$ weeks.

Group C. + K. -The mean alterations with S. D. in $\mathrm{K}_{\mathrm{E}}$, $K_{E} / \mathrm{kg}$ body weight, $K_{P}$, and B.P. are summarized in Table IV. All patients who had suffered substantial losses of potassium before the addition of Slow- $K$ increased their $K_{E}$ to within normal limits, while mean B.P. continued to fall during the period of study. The mean $K_{P}$ rise, however, was marginal $(0.2 \mathrm{mEq} / 1$.$) and control levels were not achieved.$

No clinical signs or symptoms of $\mathrm{K}^{+}$deficiency were noted in any of the subjects of this study. 
TABLB I-Pretherapy Values in the 23 Subjects Studied

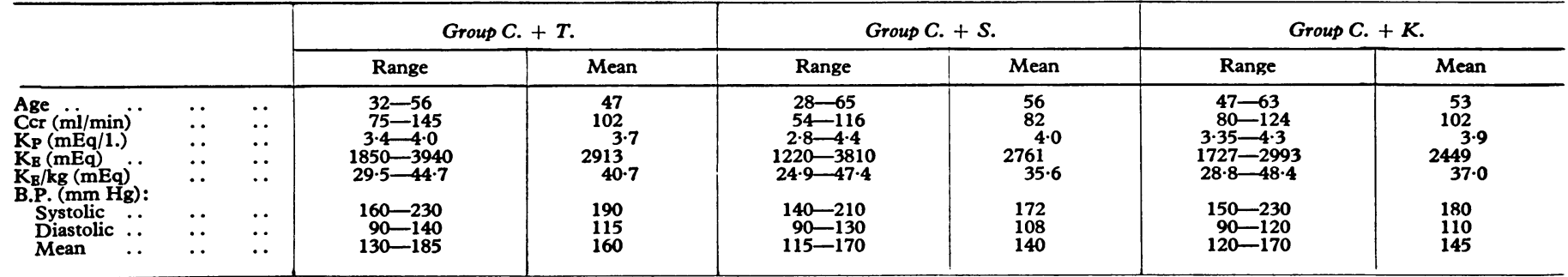

TABLE II-Mean Alterations with Standard Deviations Induced by Combined Chlorthalidone and Triamterene Therapy (C. + T.)

\begin{tabular}{|c|c|c|c|c|c|c|c|c|c|}
\hline & & & & & & & Change at 3-6 Weeks & Change at 8-11 Weeks & No. in Group \\
\hline 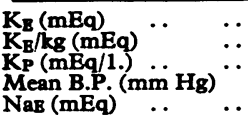 & $\begin{array}{l}. . \\
\because \\
\because \\
.\end{array}$ & $\begin{array}{l}\because \\
\ddot{ } \\
\ddot{ }\end{array}$ & $\begin{array}{l}\cdots \\
\because \\
\because\end{array}$ & $\begin{array}{l}. \\
\because \\
\because \\
.\end{array}$ & $\begin{array}{l}\cdots \\
\because \\
\cdots\end{array}$ & $\begin{array}{l}\because \\
\because \\
\because\end{array}$ & $\begin{array}{l}-228 \pm 189 P<<0.05 \\
-2.85 \pm 3.02 P<0.05 \\
-0.6 \pm 0.28 P<0.01 \\
-20.0 \pm 16 P<0.05 \\
-238 \pm 268 P<0.10\end{array}$ & $\begin{array}{l}-337 \pm 91 \mathrm{P}<0.001 \\
-4.03 \pm 2.15 \mathrm{P}<0.01 \\
-0.56 \pm 0.14 \mathrm{P}<0.001 \\
-25.0 \pm 26 \mathrm{P}<0.05 \\
-320 \pm 206 \mathrm{P}<0.05\end{array}$ & $\begin{array}{l}6 \\
6 \\
6 \\
6 \\
5\end{array}$ \\
\hline
\end{tabular}

TABLE III-Mean Alterations with Standard Deviations Induced by Combined Chlorthalidone and Spironolactone Therapy (C. + S.)

\begin{tabular}{|c|c|c|c|c|c|c|c|c|c|c|}
\hline & & & & & & & & Change at 5-8 Weeks & Change at 11-14 Weeks & No. in Group \\
\hline 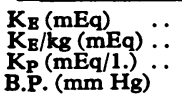 & $\begin{array}{l}\ldots \\
\cdots\end{array}$ & $\begin{array}{l}\cdots \\
\cdots \\
\cdots\end{array}$ & $\begin{array}{l}\cdots \\
\because \\
\cdots\end{array}$ & $\begin{array}{l}\ldots \\
\because \\
\cdots\end{array}$ & $\begin{array}{l}\cdots \\
\because \\
\cdots\end{array}$ & $\begin{array}{l}\cdots \\
\cdots \\
\cdots\end{array}$ & $\begin{array}{l}\cdots \\
\cdots \\
\cdots\end{array}$ & $\begin{array}{l}-67 \pm 397 \mathrm{P}<0.35 \\
+0.7 \pm 5.1 \mathrm{P}<0.35 \\
-0.11 \pm 0.34 \mathrm{P}<0.20 \\
8 \pm 16 \mathrm{P}<0.10\end{array}$ & $\begin{array}{c}-62 \pm 358 \mathrm{P}<0.30 \\
+0.6 \pm 4.5 \mathrm{P}<0.40 \\
-0.27 \pm 0.43 \mathrm{P}<0.10 \\
14 \pm 22 \mathrm{P}<0.05\end{array}$ & $\begin{array}{r}10 \\
10 \\
9 \\
10\end{array}$ \\
\hline
\end{tabular}

TABLB IV-Mean Alterations with Standard Deviations Induced by Slow-K Administration in Chlorthalidone-treated Subjects Compared with Pretherapy Values

\begin{tabular}{|c|c|c|c|c|c|c|c|c|c|}
\hline & & & & & & & $\begin{array}{l}\text { Mean Change 8-15 Weeks } \\
\text { on Diuretic }\end{array}$ & $\begin{array}{l}\text { Mean Change 5-15 Weeks } \\
\text { on Diuretic + Slow-K }\end{array}$ & No. in Group \\
\hline 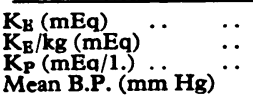 & $\begin{array}{l}\cdots \\
\cdots \\
\cdots\end{array}$ & $\begin{array}{l}\cdots \\
\cdots \\
\cdots\end{array}$ & $\begin{array}{l}\cdots \\
\because \\
\cdots\end{array}$ & 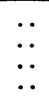 & $\begin{array}{l}. \\
\because \\
\therefore\end{array}$ & $\begin{array}{l}\because \\
\therefore \\
\therefore\end{array}$ & $\begin{array}{l}-354 \pm 404 P<<0.05 \\
-5.69 \pm 5.72 P<<0.05 \\
-0.62 \pm 0.56 P<0.05 \\
-10 \pm 10 P<0.05\end{array}$ & $\begin{array}{l}+47 \pm 124 \text { N.S. } \\
-0.97 \pm 3.54 \text { N.S. } \\
-0.42 \pm 0.64 \mathrm{P}<0.10 \\
-16 \pm 9 \mathrm{P}<0.01\end{array}$ & $\begin{array}{l}\mathbf{7} \\
\mathbf{7} \\
\mathbf{5} \\
\mathbf{7}\end{array}$ \\
\hline
\end{tabular}

TABLE v-Comparison of Mean Alterations and Standard Deviations during Therapy with Chlorthalidone and Triamterene (C. + T.), Chlorthalidone and Spironolactone $(C .+S$.$) , and Chlorthalidone Alone$

\begin{tabular}{|c|c|c|c|c|c|c|c|c|c|}
\hline & & & & & & & Chlorthalidone & Chlorthalidone + Triamterene & Chlorthalidone + Spiranolactone \\
\hline $\begin{array}{l}\mathbf{K}_{E} \text { change at 3-6 weeks } \\
K_{B} \text { change at } 8-15 \text { weeks } \\
K_{P} \text { change at } 3-6 \text { weeks } \\
K_{P} \text { change at } 8-15^{*} \text { weeks } \\
\text { No. in group .. }\end{array}$ & $\begin{array}{l}\cdots \\
\because \\
\cdots\end{array}$ & $\begin{array}{l}\ldots \\
\cdots \\
\cdots\end{array}$ & $\begin{array}{l}\ldots \\
\because \\
\cdots\end{array}$ & $\begin{array}{l}\ldots \\
\because \\
\cdots\end{array}$ & $\begin{array}{l}\ldots \\
\cdots \\
\cdots \\
\cdots\end{array}$ & $\begin{array}{l}. \\
\because \\
\because \\
\cdots\end{array}$ & $\begin{array}{l}-236 \pm 486 \mathrm{P}<0.10 \\
-317 \pm 361 \mathrm{P}<0.01 \\
-0.49 \pm 0.45 \mathrm{P}<0.01 \\
-0.65 \pm 0.47 \mathrm{P}<0.0005 \\
\end{array}$ & $\begin{array}{l}-228 \pm 189 \mathrm{P}<0.05 \\
-337 \pm 91 \mathrm{P}<0.001 \\
-0.6 \pm 0.28 \mathrm{P}<0.01 \\
-0.56 \pm 0.14 \mathrm{P}<0.001 \\
6\end{array}$ & $\begin{array}{c}-67 \pm 397 \mathrm{P}<0.35 \dagger \\
-62 \pm 358 \mathrm{P}<0.30 \dagger \\
-0.11 \pm 0.34 \mathrm{P}<0.20 \dagger \ddagger \\
-0.27 \pm 0.43 \mathrm{P}<0.10 \\
\\
10\end{array}$ \\
\hline
\end{tabular}

4-11 weeks for chlorthalidone and triamterene.

+5-8 and 11-14 weeks for chlorthalidone and spironolactone.

$\$ N=9$.

\section{Discussion}

Wiebelhaus et al. (1961) originally described triamterene as a potent diuretic, which produced a sodium diuresis with little $K$ loss in aldosterone-loaded dogs. Since then considerable interest has been shown in this agent as a means of preventing diuretic-induced $\mathrm{K}^{+}$loss in human subjects. Cattell and Havard (1962) and Wener et al. (1965) deduced from their short-term studies that the kaliuretic effect of hydrochlorothiazide was diminished by the addition of triamterene. Talso et al. (1963) administered triamterene $150 \mathrm{mg}$ daily to subjects with familial periodic paralysis and noted a marginal rise in $\mathrm{K}_{\mathrm{E}}$ and fall in $\mathrm{Na}_{\mathrm{E}}$. No other study of this agent has been performed with serial $K_{E}$ estimations. We therefore have no data on the possible efficacy of triamterene as a long-term potassiumsparing diuretic agent when administered alone. Given in combination, however, as is customary with this weak diuretic substance, the present data indicate that significant and equal
$\mathrm{K}_{\mathrm{E}}$ reduction occurred in subjects treated with both chlorthalidone and chlorthalidone plus triamterene. The decrease shown in $\mathrm{Na}_{\mathrm{E}}$ is of interest in that it seemed to be progressive from 3-6 to 8-11 weeks, and this was the reverse of the pattern previously seen with chlorthalidone therapy alone. Whereas the hypotensive effect of diuretic agents is unlikely to be related simply to the diminution in $\mathrm{Na}_{\mathrm{E}}$ (Healy et al., 1970), a maintained or progressive diminution in total exchangeable sodium would nevertheless be theoretically desirable in a number of situations, including chronic congestive heart failure, the nephrotic syndrome, and idiopathic hypercalciuria.

Edmonds and Wilson (1960) postulated that $\mathrm{K}+$ deficiency in diuretic-treated subjects might be due to secondary hyperaldosteronism resulting from concomitant sodium depletion. Gifford et al. (1961) found no such increase, however, in urinary aldosterone excretion in nine subjects despite reduction in plasma volume and (in one case) $\mathrm{NaE}$. In pursuance of this 
concept spironolactone, an aldosterone antagonist, has been recommended as a therapeutic agent since any potassium-sparing effect, in combination with its known hypotensive properties (Grieble and Johnston, 1962; Hollander, 1963) would theoretically be of especial value in the management of hypertensive patients. Hollander (1963) noted a rise in $K_{P}$ in thiazidetreated subjects when spironolactone was added. In a different context Talso et al. (1963) showed a suggestive increase in $K_{E}$ with spironolactone therapy in five subjects with periodic paralysis. Our results show that while some $K_{E}$ reduction does occur in subjects given spironolactone with chlorthalidone, the magnitude of this loss does not appear to be as great as in subjects treated with chlorthalidone alone.

Prescription of potassium chloride as a prophylactic measure to subjects on long-term diuretic therapy is not universally accepted. There is evidence that combined thiazide and entericcoated potassium preparations may cause small-bowel ulceration and stricture formation (Lindholmer et al., 1964; Lawrason et al., 1965; Morgenstern et al., 1965). Myers et al. (1967) studied the effects of high intraluminal $\mathrm{K}^{+}$concentration in loops of small intestine at operation and found evidence of cellular injury throughout the bowel wall.

Slow-K, a non-enteric-coated preparation, is stated by the manufacturers ( $\mathrm{Ciba}$ ) to cause a gradual release of potassium from its resin core. It contains potassium as the chloride salt, since coincident chloride deficiency has been shown to prevent full $\mathrm{K}$ repletion (Gulyassy et al., 1962). The results show that the addition of Slow- $K$ to subjects on continued chlorthalidone therapy effectively repletes body stores of $\mathrm{K}$ without reversal of the hypotensive effects.

These results are not strictly comparable with the C. $+\mathrm{T}$. and $C .+S$. groups in that the potassium-sparing agent was not added until $\mathrm{K}_{\mathrm{E}}$ depletion had been established by previous diuretic administration for 8-15 weeks. They nevertheless provide a useful index of the response to be expected in subjects already on therapy who are found to be hypokalaemic. It should be noted, however, that subsequent effective replacement of body $\mathrm{K}$ content is not reflected in restoration to normal of the lowered plasma concentration (Table IV). This provides an interesting, though frustrating, further indication of the lack of correspondence of these two indices as previously noted (Moore et al., 1963; Healy et al., 1970).
No subject in this study developed significant symptoms that could be ascribed to $\mathrm{K}$ deficiency. In our previous study also (Healy et al., 1970) urinary concentration and acidification as well as glucose tolerance and plasma insulin levels remained unaltered. While there is therefore no compelling evidence that potassium should be added as a routine prophylactic measure in this type of subject, the avoidance of $\mathrm{K}$ depletion may be important in other situations such as hepatic cirrhosis, diabetes mellitus (Wolff and Parmley, 1964), or subjects receiving digitalis preparations (Friedberg, 1966). Either spironolactone or Slow-K would seem to be effective agents. The absence of side-effects and smaller cost of Slow-K therapy appear to make it the treatment of choice.

We are indebted to Dr. J. G. Domenet for his interest and advice and to Sister F. Osborne and the staff of the metabolic unit. This study was supported by the Medical Research Council of Ireland.

\section{References}

Cattell, W. R., and Havard, C. W. H. (1962). British Medical fournal, 2, 1362.

Edmonds, C. J., and Wilson, G. M. (1960). Lancet, 1, 505.

Friedberg, C. K. (1966)... In Diseases of the Heart, p. 401. Philadelphia, Saunders. Gaunders.
Gifford, R. W., Mattox, V. R., Orvis, A. L., Sones, D. A., and Rosevear,

Grieble, H. G., and Johnston, L. C. (1962). Archives of Internal Medicine, $110,26$.

Gulyassy, P. F., Van Ypersele de Strihou, C., and Schwartz, W. B. (1962). Journal of Clinical Investigation, 41, 1850 .

Healy, J. J., et al. (1970). British Medical fournal, 1, 716.

Hollander, W. (1963). Heart Bulletin, 12, 108.

Lawrason, F. D., Alpert, E., Mohr, F. L., and McMahon, F. G. (1965). Fournal of the American Medical Association, 191, 641.

Lindholmer, B., Nyman, E., and Räf, L. (1964). Acta Chirurgica Scandi-

navica, 128, 310.
Moore, F. D. al al. (1963). Body Cell Mass and its Supporting Environment,

p. 135. Philadelphia, Saunders.
Morgenstern, L., Freilich, M., and Panish, J. F. (1965). Fournal of the American Medical Association, 191, 637. American Medical Association, 191, 637. Brown, C. E., and Deaver, J. M. (1967). Annals of Surgery,
166, 693.

Talso, P. J., Glynn, M. F., Oester, Y. T., and Fudema, J. (1963). Annals of the New York Academy of Sciences, 110, 993.

Wener, J., Schucher, R., and Friedman, R. (1965). Canadian Medical

Association fournal, 92, 452 .
Wiebelhaus, V. D., Weinstock, J., Brennan, F. T., Sosnowski, G., and Larsen, T. J. (1961). Federation Proceedings, 20, 409.

Wolf, F. W., and Parmley, W. W. (1964). Diabetes, 13, 115.
Division of Obstetrics and Gynaecology, United Oxford Hospitals A. J. TYACK, M.B., M.R.C.o.G., Registrar

P. BAILLIE, P.C.O.G.(s.A.), M.R.C.O.G., Nuffield Dominions Fellow F. P. MEEHAN, M.B., M.R.C.o.G., Lecturer dose-dependent. The effective dose varied between 10 and $20 \mu \mathrm{g} /$ minute. Tachyphylaxis was not observed. The only significant effects noted in the mother were tachycardia and increased pulse pressure and in the fetus a smaller increase in heart rate.

\section{Introduction}

Orciprenaline, a resorcyl ethanolamine and beta-adrenergic stimulant, has been shown to stop uterine contractions and possibly to be effective in the treatment of premature labour (Baillie et al., 1970). In that study clinical considerations required that therapeutic levels be attained rapidly. The uterine response to varying doses of orciprenaline and, more especially, to the presence or absence of tachyphylaxis was not 